\title{
Study on Deactivation and Regeneration of Modified Red Mud Catalyst Used in Biodiesel Production
}

\author{
Agus Wahyudi1,2,*, Winarto Kurniawan1, Hirofumi Hinode1 \\ ${ }^{1}$ Department of International Development Engineering, Tokyo Institute of Technology, Tokyo, Japan \\ ${ }^{2} \mathrm{R} \&$ D Centre for Mineral and Coal Technology, Ministry of Energy and Mineral Resources, Bandung, Indonesia \\ Email: *a.wahyudi80@gmail.com
}

How to cite this paper: Wahyudi, A., Kurniawan, W. and Hinode, H. (2017) Study on Deactivation and Regeneration of Modified Red Mud Catalyst Used in Biodiesel Production. Green and Sustainable Chemistry, 7, 247-258.

https://doi.org/10.4236/gsc.2017.74019

Received: August 10, 2017

Accepted: September 19, 2017

Published: September 22, 2017

Copyright ( 2017 by authors and Scientific Research Publishing Inc. This work is licensed under the Creative Commons Attribution International License (CC BY 4.0). http://creativecommons.org/licenses/by/4.0/

\begin{abstract}
Deactivation of solid catalyst often occurs in biodiesel production. In this work, deactivated modified red mud catalysts used in biodiesel production were regenerated with hexane and calcination treatments. The deactivated and regenerated catalysts were characterized using XRD, FTIR, SEM, TG, $\mathrm{N}_{2}$ adsorption, measured for their basic strength, and tested in the transesterification of canola oil. The results revealed that the main cause of the catalyst deactivation is due to obstruction of the active sites by contaminants. The regeneration by washing with hexane followed by calcination can effectively improve the properties of the deactivated catalyst and increase its catalytic activity.
\end{abstract}

\section{Keywords}

Modified Red Mud Catalyst, Deactivation, Regeneration, Biodiesel

\section{Introduction}

Heterogeneous catalysts have attracted an attention to be used in industries due to some advantages compare to homogeneous catalyst [1]. Since it exists in different phase from the mixtures, heterogeneous or solid catalyst can easily be separated and reused [2]. However, the activity of the used catalyst is generally lower than the fresh one [3].

In biodiesel production, the deactivation of solid catalyst often occurs and it is caused by some factors, such as leaching of active sites, strutural collapse, and surface poisoning by contaminants [4]. Kouzo et al. [5] reported that some 
soluble substances were leached out from the $\mathrm{CaO}$ solid base catalyst during the transesterification reaction. The alkali metals from the catalyst easily react with esters and trglycerides to form soaps, which signicantly leads to the deactivation of the catalyst [1]-[6]. Another factor of catalyst deactivaton is structural collapse. The porous structure of the catalyst can be collapsed by high temperature or mechanical mixing during reaction [7] [8]. The next reason of catalyst deactivation is surface poisoning by contaminants. The contaminants are organic compounds from the products or by-products of the transesterification reaction, such as methyl esters, glycerol or diglyceride [9]. The contaminants attach on the catalyst surface, fill the pore, and cover the active sites of the catalyst. Such conditions led to the low accessibility of the active sites of metal oxides to the reactants, which significantly inibit the activity of the catalyst [4].

In the previous work [10], we have applied red mud, a waste material from alumina industry, as a solid catalyst for biodiesel production. The red mud was modified using soda-lime calcination and successfully produce biodiesel that showed high fatty acid methyl esters (FAME) content, the compounds of biodiesel, from transesterication of canola oil. In this work, deactivation of modified red mud catalyst was studied to obtain the factor(s) that is/are responsible to degradation of its properties and activities. The regeneration of the deactivated catalyst was conducted by calcination, washing with hexane, and combination of them to show the effective method to recover its catalytic activity. The activity of the deactivated and regenerated catalyst were tested in the transesterification of canola oil. The physical and chemical properties of the catalysts such as thermogravimetry behaviour, crystallinity, morphology, specific surface area, and basic strength were also investigated.

Oueda et al. [4] reported that some catalysts based on $\mathrm{CaO}$ and $\mathrm{MgO}$ need to be regenerated by several methods, such as washing with hexane, acetone, methanol and followed by calcination up to $900^{\circ} \mathrm{C}$. The activity of the regenerated catalysts was then tested in transesterification of vegetable oils and showed such low activity compare to that using the fresh catalysts. Therefore, the necessity of this study is to find out the effective method to regenerate the used catalyst, especially for modified red mud catalyst, and recover its catalytic activity.

\section{Materials and Methods}

\subsection{Catalyst Preparation}

The fresh catalyst was prepared according to the method described in the previous work [10]. It was prepared by modification of red mud through soda lime calcination at $700^{\circ} \mathrm{C}$ for $2 \mathrm{~h}$. The fresh catalyst was then labelled as FC.

\subsection{Catalytic Activity Test}

The catalytic activity of the fresh, deactivated, and regenerated catalysts were performed by transesterification of canola oil with methanol to produce 
biodiesel. Commercial canola oil was obtained from the market. The catalytic reactions were carried out in a $100 \mathrm{~mL}$ one-necked round-bottomed flask with a reflux condenser using optimum reaction conditions as obtained from the previous work [10]. The optimum reaction conditions were 12:1 of methanol/oil molar ratio, $4 \mathrm{wt} \%$ of catalyst amount, $60^{\circ} \mathrm{C}$ of reaction temperature, and $2 \mathrm{~h}$ of reaction time.

After the reaction completed, the solid part was separated by filtration. The liquid part was put into a funnel separator and kept for $24 \mathrm{~h}$ at room temperature. The liquid separated into two layers, the lower layer was glycerol, and the upper layer was biodiesel. The yield of biodiesel or fatty acid methyl esters (FAME) was determined using the European procedure EN 14103 [11] by gas chromatography-mass spectrometry (GCMS-QP2010 SE, Shimadzu) with a Rxi-5Sil MS capillary column $(30 \mathrm{~m}, 0.25 \mathrm{~mm}, 0.25 \mu \mathrm{m})$.

\subsection{Catalyst Regeneration}

The deactivated or used catalyst was dried at $100^{\circ} \mathrm{C}$ overnight and labelled as DUC. The used catalysts were then regenerated through three different methods. First, the DUC was calcined at $700^{\circ} \mathrm{C}$ for $2 \mathrm{~h}$, labelled as DUC-cal. Second, the used catalyst was washed using hexane and dried at $100^{\circ} \mathrm{C}$ overnight, labelled as WUC. Third, the WUC was calcined at $700^{\circ} \mathrm{C}$ for $2 \mathrm{~h}$, labelled as WUC-cal. The deactivated and regenerated catalysts were then tested for their catalytic activity through transesterification of canola oil according to the procedure mentioned in 2.2 .

\subsection{Characterization of Catalyst}

Characterization of the recovered catalyst was conducted using various methods. Crystallinity and mineral contents identification was conducted using X-ray diffraction (XRD) Rigaku Multiflex X-ray diffractometer with $\mathrm{Cu}-\mathrm{K} \alpha$ radiation $(\lambda=1.54056 \AA)$ at $40 \mathrm{kV}, 20 \mathrm{~mA}$ over the 2-theta range of $15^{\circ}-40^{\circ}$. Thermogravimetry (TG) analysis were determined using Rigaku Thermoplus TG 8120 under air flow at a heating rate of $10^{\circ} \mathrm{C} / \mathrm{min}$ up to $900^{\circ} \mathrm{C}$. This analysis aims to measure the weight loss of the samples during heating. The basic strength of the catalyst was estimated using bromothymol blue $\left(\mathrm{H}_{-}=7.2\right)$, phenolphthalein $\left(\mathrm{H}_{-}=9.3\right)$, 2,4-dinitroaniline $\left(\mathrm{H}_{-}=15.0\right)$, and 4-chloro-2nitroaniline $\left(\mathrm{H}_{-}=17.2\right)$ as Hammett indicators [12] [13]. Scanning electron microscope (SEM) image was obtained using Keyence VE-8800 for morphological observation. Specific surface area of the catalyst was measured using $\mathrm{N}_{2}$ adsorption Autosorb-1C (Quantachrome Instruments, AX1C-MP-LP) and calculated by Brunauer-Emmet-Teller (BET) method. BET method aims to explain the physical adsorption of gas molecules on a solid surface and can be used to measure the specific surface area of the solid samples. Fourier-transform infrared (FTIR) spectrum was recorded using Jasco FT/IR-6100FV in the region of $500-$ $4000 \mathrm{~cm}^{-1}$. 


\section{Results and Discussion}

\subsection{Results of Catalytic Activity Test}

Figure 1 shows catalytic activity of the fresh, deactivated, and regenerated catalysts used in transesterification of canola oil. The catalytic activity of deactivated catalyst decreased significantly compared to the fresh one. The FAME yield of the produced biodiesel were $48.9 \%$ and $99.6 \%$, respectively. After regeneration by calcination, the FAME yield of the produced biodiesel increased up to $78.9 \%$. By washing with hexane and in combination with calcination, the activity were even higher. The FAME yield were $81.8 \%$ and $96.8 \%$, respectively. It showed that washing with hexane is an effective method to recover the catalyst activity. Further, by combination with calcination, the performance of the catalyst return almost as high as the fresh catalyst. The physical and chemical properties of the catalysts will be discussed more detail in section 3.2 to 3.5 to answer the factor(s) that responsible to degradation of the catalyst properties and activities.

\subsection{Results of TG}

Figure 2 shows TG profiles of the catalysts. Each catalyst had different weight loss in the range from room temperature to $900^{\circ} \mathrm{C}$. The fresh catalyst had nearly no weight loss up to $700^{\circ} \mathrm{C}$ and slight loss at $900^{\circ} \mathrm{C}$. The significant weight loss of about $40 \%$ occured in the deactivated catalyst, due to deposition of organic compounds from the working solution. It revealed that the contaminants is the main cause of catalyst deactivation [14] [15]. This result support the fact of its decrease in catalytic activity. The regerenerated catalyst by calcination or by washing with hexane shows weight loss about $20 \%$ due to the remaining deposition of organic compounds from the solution. The contaminants can be released effectively by combination of washing and calcination. It was indicated

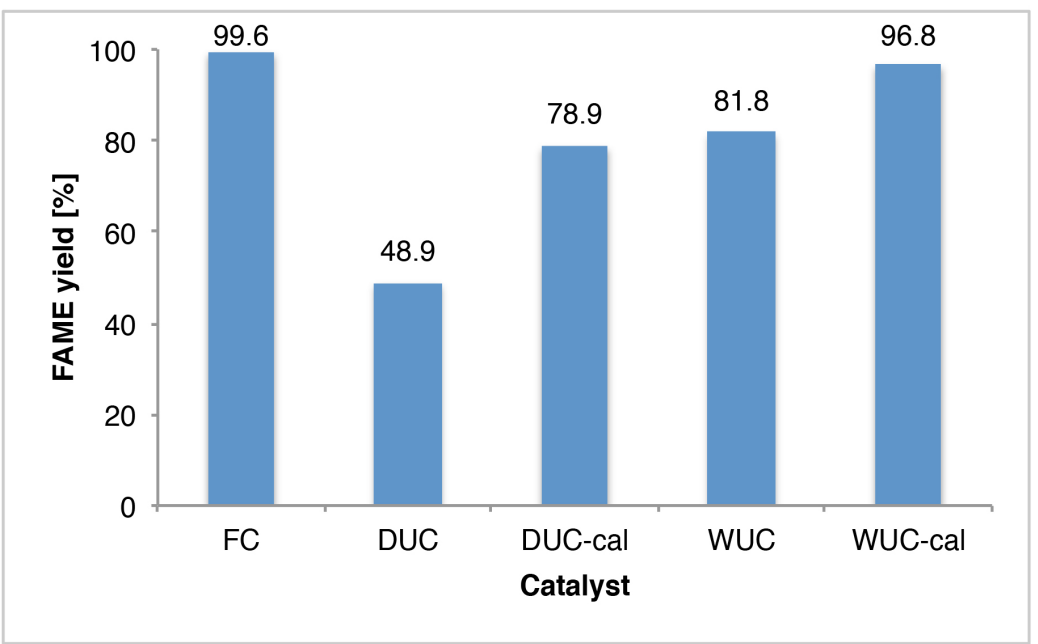

Figure 1. FAME yield of transesterification of canola oil over the catalysts (reaction conditions: methanol/oil molar ratio of $12: 1$, catalyst amount of $4 \%$, temperature of $60^{\circ} \mathrm{C}$, and reaction time of $2 \mathrm{~h}$ ). 


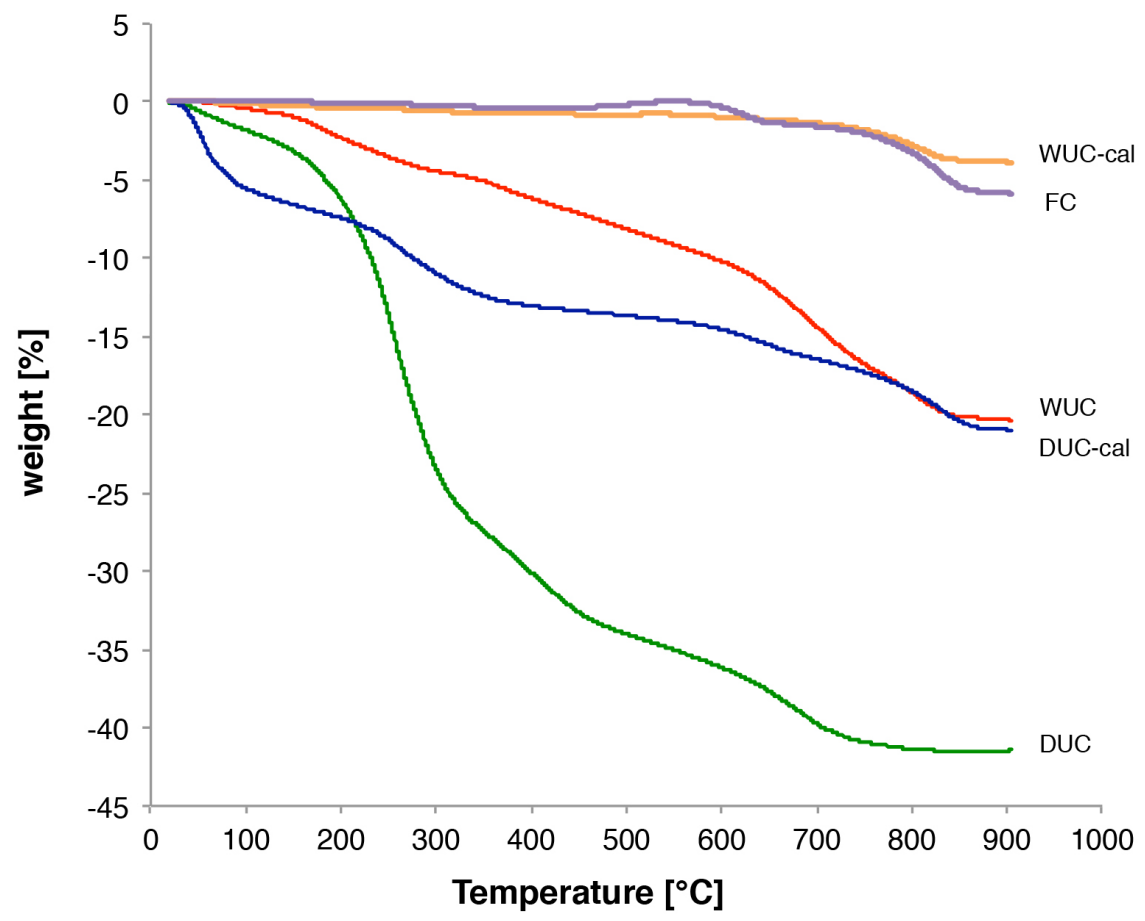

Figure 2. TG profiles of the fresh, deactivated, and regenerated catalysts.

by the TG profile which showed very slight weight loss during heating.

\subsection{Results of FTIR}

To study the reason for the decrease of FAME yield, FTIR spectroscopy was used to explain the change of chemical bond structure on the catalyst surface. The change can be caused by surface interaction with constituents such as residues or products of the reactions. Figure 3 shows FTIR spectra of the catalysts. In the case of fresh catalyst (Figure 3(a)), a sharp band was observed at $3644 \mathrm{~cm}^{-1}$, due to the vibration of the $\mathrm{OH}$ groups that attached to $\mathrm{Ca}^{2+}$ and $\mathrm{Na}^{+}$. This could be assigned to the $\mathrm{OH}$ group vibrations of the bound $\mathrm{H}_{2} \mathrm{O}$ on the surface of the sample. In addition, the band at $1674 \mathrm{~cm}^{-1}$ confirmed the adsorption of water on the catalyst surface [16]. The bands around 1445, 989, and $881 \mathrm{~cm}^{-1}$ represent the vibrations of the carbonates ion [17]. The carbonate species derived from the interaction between the surface basic sites with $\mathrm{CO}_{2}$ from the atmosphere [16]. The FTIR spectra of regenerated catalysts (Figures 3(c)-(e)) still reserved the characteristic spectra of the fresh one, and almost no significant changes during regeneration processes.

The significant change of the FTIR spectra occured in the deactivated catalyst (Figure 3(b)). The deactivated catalyst presented new bands in the range 2950 $2850 \mathrm{~cm}^{-1}$, corresponds to the $\mathrm{C}-\mathrm{H}$ vibrations [16]. Besides, new bands were also observed at around 1745 and $1561 \mathrm{~cm}^{-1}$, which were associated with the $\mathrm{C}=\mathrm{O}$ group vibrations [18]. All the new bands resulted from the adsorption of methyl esters, glycerides, or glycerol on the catalyst surface, as the products and by-products of transesterication reaction [9]. These results revealed that after 


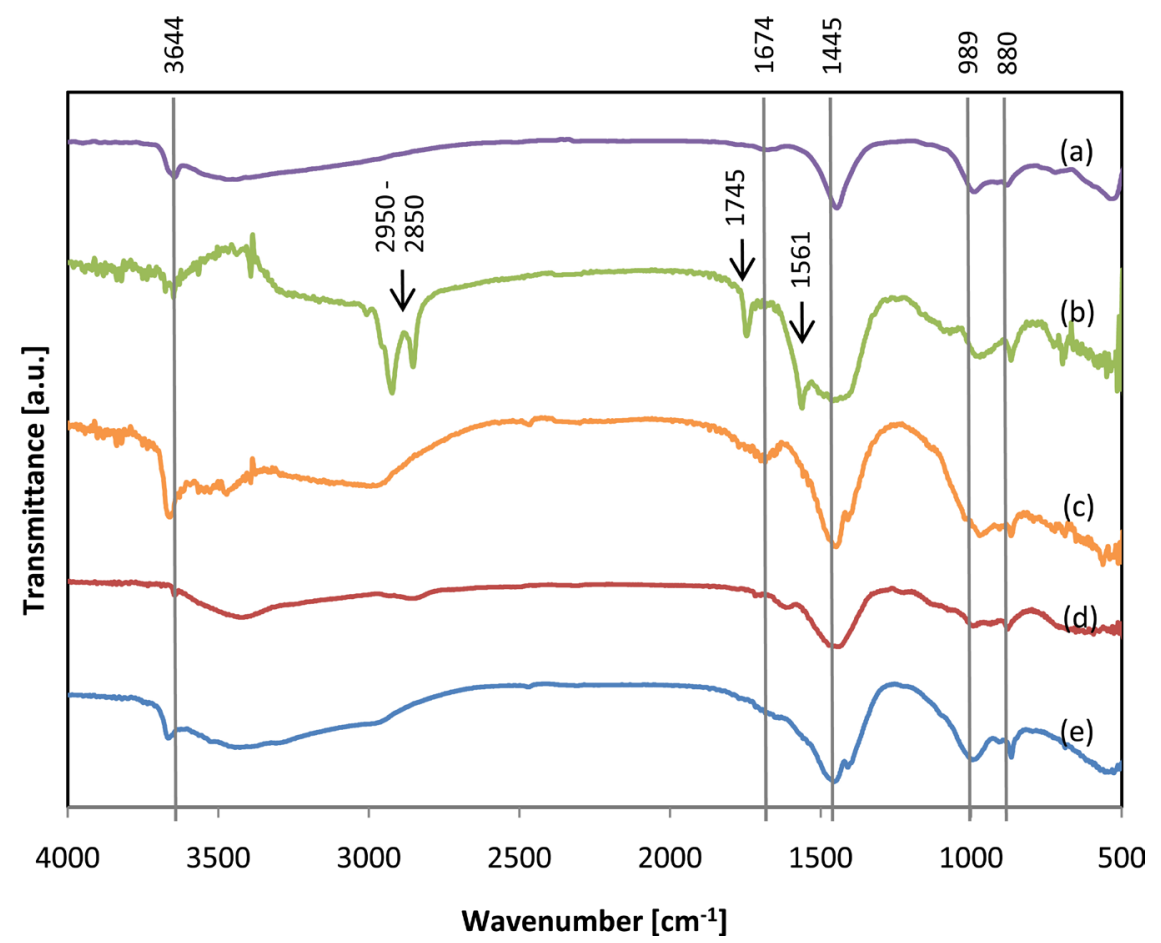

Figure 3. FTIR spectra of the catalysts: (a) FC, (b) DUC, (c) DUC-cal, (d) WUC, (e) WUC-cal.

reaction, the contaminants still attached on the catalyst surface and affected the availability of its active compounds. Such conditions made the catalyst loss its activity.

\subsection{Results of SEM and $\mathrm{N}_{2}$ Adsorption}

Figure 4 shows morphology of the catalysts. The fresh catalyst exhibited spongy and porous structures indicating surfaces with high adsorption capability. The particles shown have uniform distribution of agglomerates with irregular shapes (Figure 4(a)). Agglomeration structures with spaces between agglomerates are effective solid catalysts for transesterification [19]. The channels can be optimized for the entry of triglyceride and methanol during reaction which is containing basic sites at the internal surface [20]. After the reaction, the deactivated catalyst appeared to be more condensed (Figure 4(b)), due to covarage of the active sites by contaminants, which had significant effect on the loss of catalytic activity [21]. The regeneration by calcination improved the catalyst surfaces by burning out the contaminants as shown in Figure 4(c). On the other hand by washing with hexane, and in combination with calcination, produced porous structures with highly distribution of agglomerates (Figure $4(\mathrm{~d})$ and Figure $4(\mathrm{e})$ ). The treatments made the active sites exposed and easily accessed by the reactants during reaction, indicated by the increase of FAME yield (Figure 1).

The $\mathrm{N}_{2}$ adsorption analysis supported the SEM results as shown in Table 1 . The specific surface area of deactivated catalyst decreased significantly from 4.45 

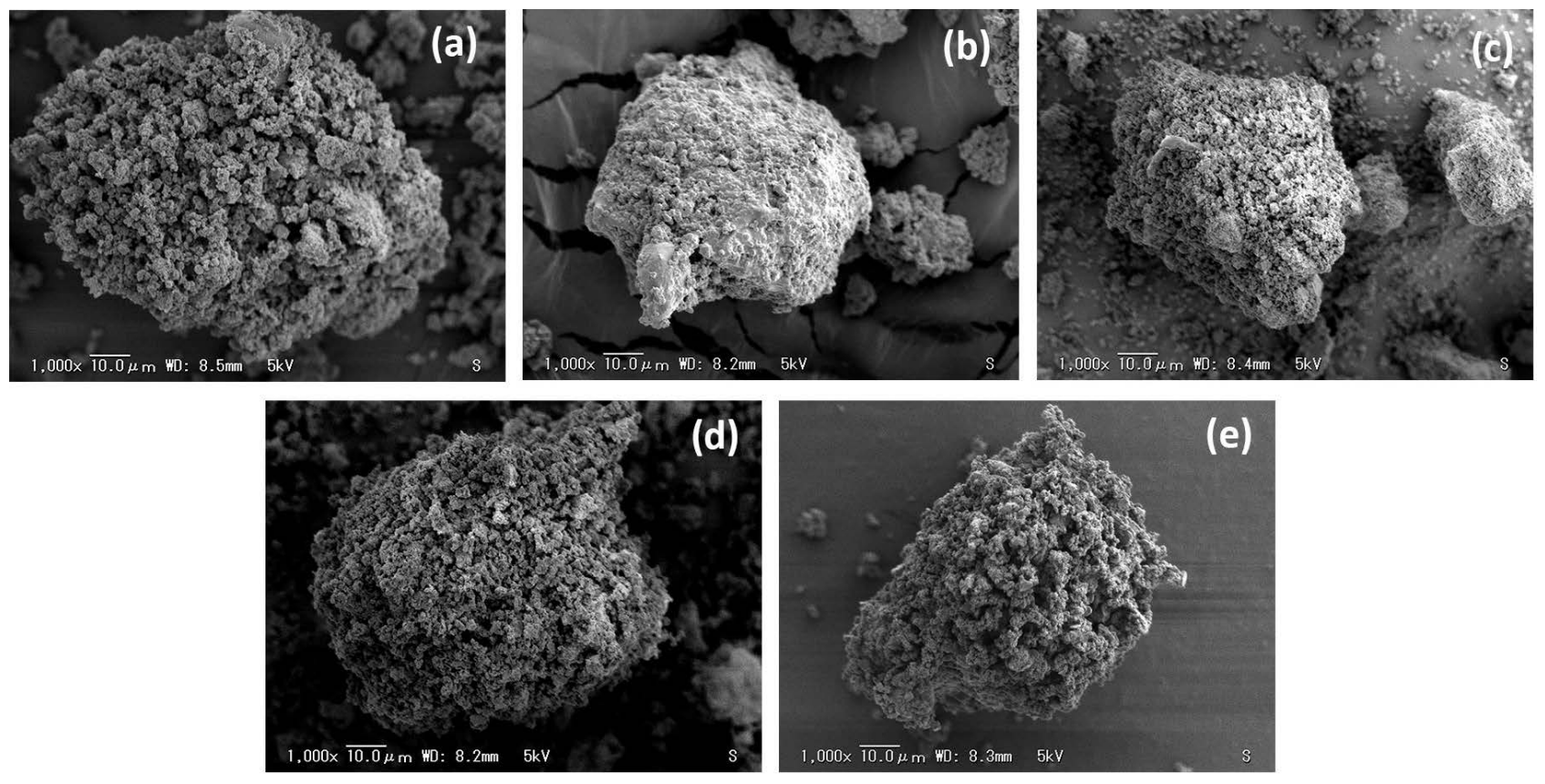

Figure 4. SEM images at 1000 magnification of the catalysts: (a) FC, (b) DUC, (c) DUC-cal, (d) WUC, (e) WUC-cal.

Table 1. Specific surface area and basic strength of the catalysts.

\begin{tabular}{ccc}
\hline Catalyst & Specific surface area, BET $\left(\mathrm{m}^{2} / \mathbf{g}\right)$ & Basic strength $\left(\mathrm{H}_{-}\right)$ \\
\hline FC & 4.45 & $15.0-17.2$ \\
DUC & 0.94 & $7.2-9.3$ \\
DUC-cal & 2.71 & $9.3-15.0$ \\
WUC & 6.36 & $9.3-15.0$ \\
WUC-cal & 10.18 & $15.0-17.2$ \\
\hline
\end{tabular}

$\mathrm{m}^{2} / \mathrm{g}$ (fresh catalyst) to $0.94 \mathrm{~m}^{2} / \mathrm{g}$. Researchers had investigated the reason behind the loss in catalytic activity from the fresh to deactivated catalyst. They concluded that the loss of catalytic activity could be related to the decrease of the specific surface area of the deactivated catalyst [22] [23]. The regeneration of deactivated catalyst by washing and/or calcination effectively increased the specific surface area due to liberation of the surface from the contaminants, which considerably increased the catalytic activity.

\subsection{Results of XRD and Basic Strength}

Figure 5 shows XRD patterns of the catalysts. The XRD pattern of the fresh catalyst shows some active compounds for transesterification reaction, such as calcium oxide, sodium aluminate, and sodium silicate (Figure 5(a)). Those compounds were reported to have high basicity and high activity as solid catalyst for biodiesel production [5] [20] [24]. Basicity or basic strength in biodiesel catalyst has important role to deprotonate methanol into methoxide ion $\left({ }^{-} \mathrm{OCH}_{3}\right)$, a species that can reacts with triglyceride to form methyl esters (biodiesel) [25]. The higher basic strength of the catalyst the higher its catalytic activity. 


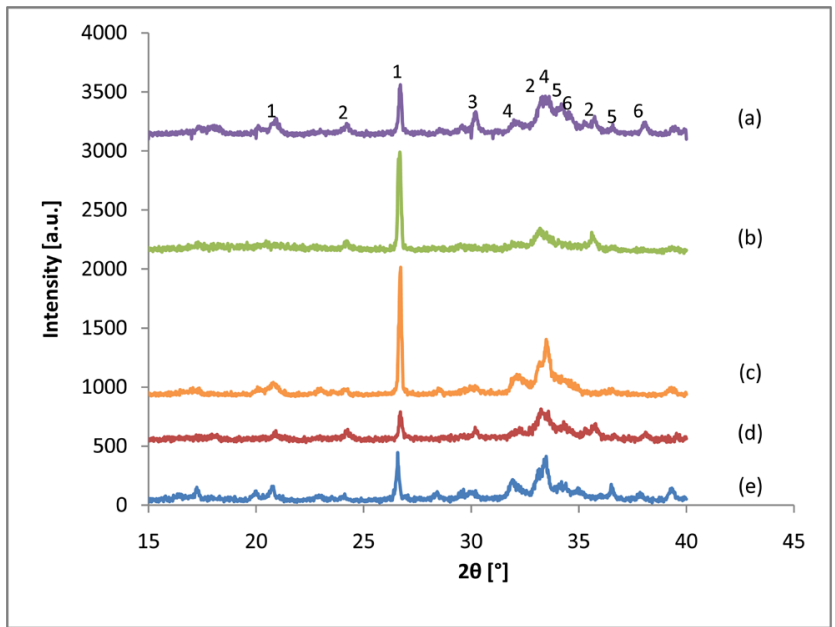

Figure 5. XRD patterns of the catalysts: (a) FC, (b) DUC, (c) DUC-cal, (d) WUC, (e) WUC-cal.

The XRD pattern of deactivated catalyst shows significant decrease in the active compounds' relative intensity to quartz peak (Figure 5(b)). Some of them also dissapeared due to obstruction of the catalyst surface by contaminants. This phenomenon was also reported by Dias et al. and Deng et al. [26] [27]. Such conditions led to the low accessibility of the active sites to the reactants, as indicated by the decrease of its basic strength using Hammet indicators (Table 1). The regeneration by calcination improved the crystallinity of the catalyst. Some active compounds appeared but the intensity still low (Figure 5(c)). The catalyst structures improved by washing with hexane, followed by calcination as shown in Figure 5(d) and Figure 5(e), respectively. The intensity of the active compounds increased as well as the basic strength as shown in Table 1, and affected its catalytic activity.

\subsection{Comparison Study: Regeneration of Modified Red Mud Catalyst and CaO Based Catalysts and Their Catalytic Activity}

Calcium oxide is the most common solid base catalyst used in research of biodiesel production [14]. Table 2 summarizes the performance of regenerated $\mathrm{CaO}$ based catalysts in biodiesel production using different regeneration methods. The performance of regenerated modified red mud catalyst prepared in this study is also presented. Compare to regenerated $\mathrm{CaO}$ based catalyst, regenerated modified red mud catalyst had better performance. The FAME yield for repeated uses shows high value without any significant loss of activity.

\subsection{The Role of Hexane (Washing Agent) and Calcination for Catalyst Regeneration}

Hexane is an organic compound made of carbon and hydrogen (Figure 6) which is commonly used as a solvent. One of the popular uses is as industrial cleaner or degreaser. Hexane is a non-polar molecule and it is very effective breaking molecules down and separating oils and other organic compounds from other 
Table 2. Regeneration of $\mathrm{CaO}$ based catalyst and modified red mud catalyst, and their performance used in transesterification reaction.

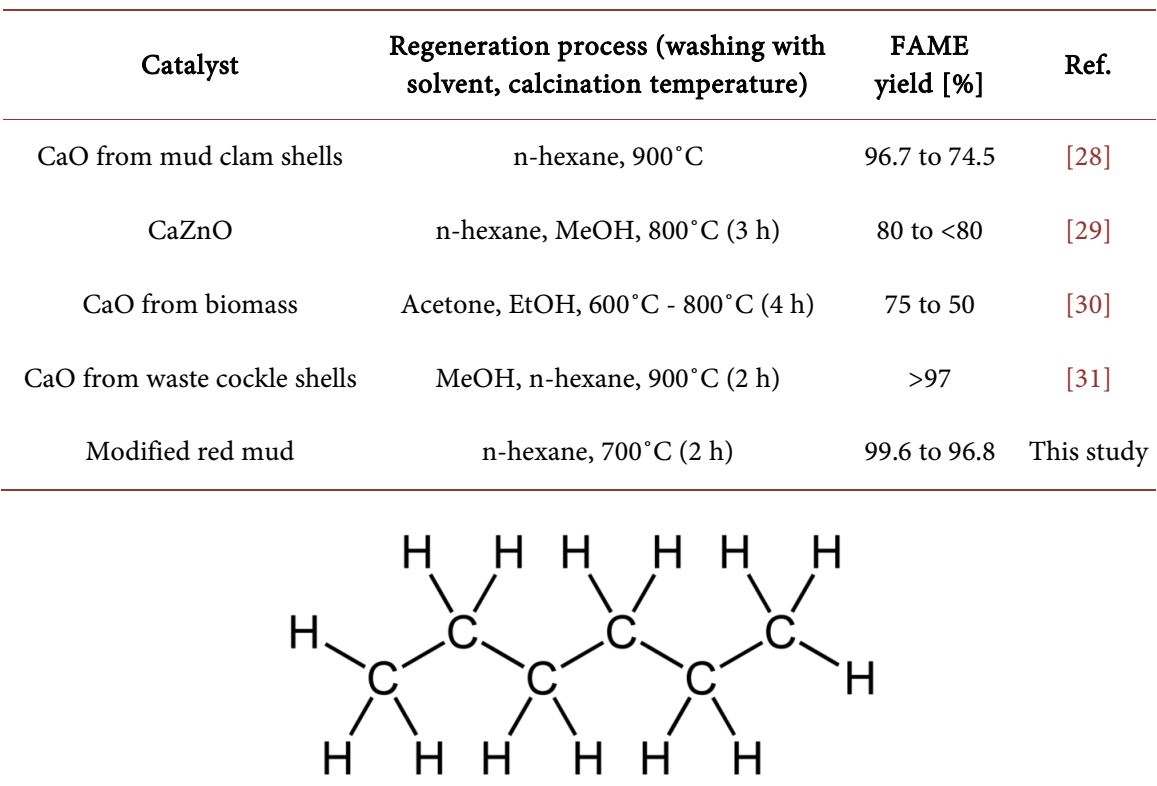

Figure 6. Structure of hexane.

substances [29]. Further, since hexane cannot be easily deprotonated, it is used in the laboratory for reactions that involve very strong base [32]. Those factors explain that hexane is an effective washing agent for catalyst regeneration, especially for solid base catalyst.

Another common method to regenerate catalyst is by calcination. One of the aim using this method is to activate the hydrophilic materials from the moisture or other compounds, such as carbonate ions, that attach on their surface [4]. However, calcination will not give effective result if it is directly conducted to the used catalyst. The organic compounds on the catalyst surface tend to convert into carbon and it still attach on the catalyst surface. This situation will not improve the activity of the catalyst. Calcination will give effective result if it is conducted after washing.

Figure 7 illustrates the recycle steps of the catalyst. The fresh catalyst had high efficiency for biodiesel production due to containing high basicity and well distributed porous structures. After reaction, the used catalyst loss its activity due to coverage of the contaminants on its surface, affected the basic sites cannot be exposed to react with the reactants. The activity of the used catalyst can be recovered by washing with hexane and calcination. The washing treatment will clean up the catalyst surface from the contaminants. The next step, calcination, will activate the active sites of the catalyst. The activity of the regenerated catalyst is almost the same with the fresh one. The analysis of the physical and chemical properties of the regenerated catalyst using TG, XRD, FTIR, SEM and basic strength measurement also revealed that the characteristics of the regenerated catalyst are similar to the fresh one. 


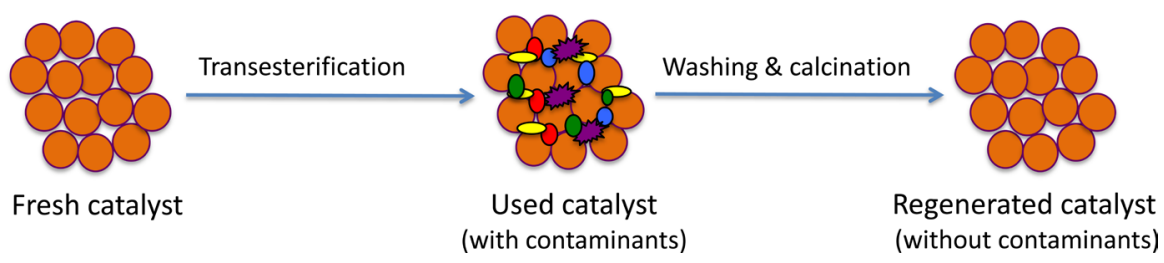

Figure 7. Illustration of deactivation and regeneration of catalyst by washing and calcination (modified from Oueda et al. [4]).

\section{Conclusions}

Deactivation of modified red mud catalyst used in transesterification reaction might be caused by several factors, but mainly it is due to deposits of organic compounds on the catalyst. The results from TG, FTIR, XRD, and SEM showed that the contaminants change the properties of the catalyst. As a consequence, the contaminants affect in decrease of the specific surface area as well as the basic strength of the catalyst, and considerably reduce its catalytic activity.

The regeneration by washing with hexane and followed by calcination can effectively regenerate the physical and chemical properties, and recover its catalytic activity close to that of the fresh one. The understanding of the mechanism of a catalyst deactivation is really important to plan its regeneration process.

\section{Acknowledgements}

The authors thank the assistance of Prof. Kunio Yoshikawa from School of Environmental and Society, Tokyo Institute of Technology, for using GCMS instrument. The first author acknowledges the Ministry of Energy and Mineral Resources, Republic of Indonesia for the scholarship.

\section{Compliance with Ethical Standards}

Conflict of interest: the authors declare that they have no conflict of interest.

\section{References}

[1] Lee, A.F., Bennett, J., Manayil, J.C. and Wilson, K. (2014) Heterogeneous Catalysis for Sustainable Biodiesel Production via Esterification and Transesterification. Chemical Society Reviews, 43, 7887-7916. https://doi.org/10.1039/C4CS00189C

[2] Semwal, S., Arora, A.K., Badoni, R.P. and Tuli, T.L. (2011) Biodiesel Production Using Heterogeneous Catalysts. Bioresource Technology, 102, 2151-2161. https://doi.org/10.1016/j.biortech.2010.10.080

[3] Argyle, M. and Bartholomew, C. (2015) Heterogeneous Catalyst Deactivation and Regeneration: A Review. Catalysts, 5, 145-269. https://doi.org/10.3390/catal5010145

[4] Oueda, N., Bonzi-Coulibaly, Y.L. and Ouédraogo, I.W.K. (2017) Deactivation Processes, Regeneration Conditions and Reusability Performance of $\mathrm{CaO}$ or $\mathrm{MgO}$ Based Catalysts Used for Biodiesel Production-A Review. Materials Sciences and Applications, 8, 94-122. https://doi.org/10.4236/msa.2017.81007

[5] Kouzu, M., Kasuno, T., Tajika, M., Sugimoto, Y., Yamanaka, S. and Hidaka, J. (2008) Calcium Oxide as a Solid Base Catalyst for Transesterification of Soybean Oil and Its Application to Biodiesel Production. Fuel, 87, 2798-2806. 
https://doi.org/10.1016/j.fuel.2007.10.019

[6] Singh, A., He, B., Thompson, J. and Gerpen, J.V. (2006) Process Optimization of Biodiesel Production Using Alkaline Catalysts. Applied Engineering in Agriculture, 22, 597-600. https://doi.org/10.13031/2013.21213

[7] Pham, H.N., Reardon, J. and Datye, A.K. (1999) Measuring the Strength of Slurry Phase Heterogeneous Catalysts. Powder Technology, 103, 95-102. https://doi.org/10.1016/S0032-5910(98)00177-6

[8] Xia, S., Guo, X., Mao, D., Shi, Z., Wu, G. and Lu, G. (2014) Biodiesel Synthesis over the $\mathrm{CaO}-\mathrm{ZrO}_{2}$ Solid Base Catalyst Prepared by a Urea-Nitrate Combustion Method. RSC Advances, 4, 51688-51695. https://doi.org/10.1039/C4RA11362D

[9] Verziu, M., Coman, S.M., Richards, R. and. Parvulescu, V.I. (2011) Transesterification of Vegetable Oils over CaO Catalysts. Catalysis Today, 167, 64-70. https://doi.org/10.1016/j.cattod.2010.12.031

[10] Wahyudi, A., Kurniawan, W. and Hinode, H. (2017) Utilization of Modified Red Mud as a Heterogeneous Base Catalyst for Transesterification of Canola Oil. Journal of Chemical Engineering of Japan, 5, 561-567. https://doi.org/10.1252/jcej.16we337

[11] European Standard (2003) EN-14103: Determination of Ester and Linolenic Acid Methyl Ester Contents. European Committee for Standardization, Brussels.

[12] Tanabe, K., Misono, M., Ono, Y. and Hattori, H. (1989) New Solid Acids and Bases Their Catalytic Properties. In: Delmon, B. and Yates, J., Eds., Studies in Surface Science and Catalysis, Kodansha Tokyo, Tokyo, 14-15.

[13] Xie, W., Peng, H. and Chen, L. (2006) Calcined Mg-Al Hydrotalcites as Solid Base Catalysts for Methanolysis of Soybean Oil. Journal of Molecular Catalysis A: Chemical, 246, 24-32.

[14] Kouzu, M. and Hidaka, J.S. (2012) Transesterification of Vegetable Oil into Biodiesel Catalyzed by CaO: A Review. Fuel, 93, 1-12.

[15] Wen, Z., Yu, X., Tu, S.T., Yan, J. and Dahlquist, E. (2010) Biodiesel Production from Waste Cooking Oil Catalyzed by TiO2-MgO Mixed Oxides. Bioresource Technology, 101, 9570-9576.

[16] Li, F.J., Li, H.Q., Wang, L.G. and Cao, Y. (2015) Waste Carbide Slag as a Solid Base Catalyst for Effective Synthesis of Biodiesel via Transesterification of Soybean Oil with Methanol. Fuel Processing Technology, 131, 421-429.

[17] Rodriguez-Blanco, J.D., Shaw, S. and Benning, L.G. (2011) The Kinetics and Mechanisms of Amorphous Calcium Carbonate (ACC) Ccrystallization to Calcite, via Vaterite. Nanoscale, 3, 265-271. https://doi.org/10.1039/C0NR00589D

[18] Coates, J. (2000) Interpretation of Infrared Spectra, A Practical Approach, In: Meyers, R.A., Ed., Encyclopedia of Analytical Chemistry, John Wiley \& Sons Ltd., Chichester, 10815-10837.

[19] Cherikkallinmel, S.K., Gopalakrishnan, A., Yaakob, Z., Ramakrishnan, R.M., Sugunan, S. and Narayanan, B.N. (2015) Sodium Aluminate from Waste Aluminium Source as Catalyst for the Transesterification of Jatropha Oil. RSC Advances, 5, 46290-46294. https://doi.org/10.1039/C5RA05982H

[20] Guo, F., Peng, Z.G., Dai, J.Y. and Xiu, Z.L. (2010) Calcined Sodium Silicate as Solid Base Catalyst for Biodiesel Production. Fuel Processing Technology, 91, 322-328.

[21] Ho, W.W.S., Gan, H.K., Ng, S. and Tan, S.H. (2014) Evaluation of Palm Oil Mill Fly Ash Supported Calcium Oxide as a Heterogeneous Base Catalyst in Biodiesel Synthesis from Crude Palm Oil. Energy Conversion and Management, 88, 1167-1178. 
[22] Kaur, M. and Ali, A. (2014) Ethanolysis of Waste Cottonseed Oil over Lithium Impregnated Calcium Oxide: Kinetics and Reusability Studies. Renewable Energy, 63, 272-279.

[23] Kutálek, P., Čapek, L., Smoláková, L. and Kubička, D. (2014) Aspects of Mg-Al Mixed Oxide Activity in Transesterification of Rapeseed Oil in a Fixed-Bed Reactor. Fuel Processing Technology, 122, 176-181.

[24] Wan, T., Yu, P., Wang, S. and Luo, Y. (2009) Application of Sodium Aluminate as a Heterogeneous Base Catalyst for Biodiesel Production from Soybean Oil. Energy and Fuels, 23, 1089-1092. https://doi.org/10.1021/ef800904b

[25] Lee, H.V., Juan, J.C., Taufiq-Yap, Y.H., Kong, P.S. and Rahman, N.A. (2015) Advancement in Heterogeneous Base Catalyzed Technology: An Efficient Production of Biodiesel Fuels. Journal of Renewable and Sustainable Energy, 7, 32701-32746. https://doi.org/10.1063/1.4919082

[26] Deng, X., Fang, Z., Liu, Y. and Yu, C.L. (2011) Production of Biodiesel from Jatropha Oil Catalyzed by Nanosized Solid Basic Catalyst. Energy, 36, 777-784.

[27] Dias, A.P.S., Bernardo, J., Felizardo, P. and Correia, M.J.N. (2012) Biodiesel Production by Soybean Oil Methanolysis over SrO/MgO Catalysts: The Relevance of the Catalyst Granulometry. Fuel Processing Technology, 102, 146-155.

[28] Ismail, S., Ahmed, A.S., Anr, R. and Hamdan, S. (2016) Biodiesel Production from Castor Oil by Using Calcium Oxide Derived from Mud Clam Shell. Journal of Renewable Energy, 2016, Article ID: 5274917. https://doi.org/10.1155/2016/5274917

[29] Taufiq-Yap, Y.H., Lee, H.V., Hussein, M.Z. and Yunus, R. (2011) Calcium-Based Mixed Oxide Catalysts for Methanolysis of Jatropha Curcas Oil to Biodiesel. Biomass and Bioenergy, 35, 827-834.

[30] Luque, R., Pineda, A., Colmenares, J.C., Campelo, J.M., Romero, A.A., Serrano-Riz, J.C., Cabeza, L.F. and Cot-Gores, J. (2012) Carbonaceous Residues from Biomass Gasification as Catalysts for Biodiesel Production. Journal of Natural Gas Chemistry, 21, 246-250.

[31] Boey, P.L., Maniam, G.P., Hamid, S.A. and Ali, D.M.H. (2011) Utilization of Waste Cockle Shell (Anadara Granosa) in Biodiesel Production from Palm Olein: Optimization Using Response Surface Methodology. Fuel, 90, 2353-2358.

[32] Hexane. https://en.wikipedia.org/wiki/Hexane

\section{Submit or recommend next manuscript to SCIRP and we will provide best service for you:}

Accepting pre-submission inquiries through Email, Facebook, LinkedIn, Twitter, etc. A wide selection of journals (inclusive of 9 subjects, more than 200 journals)

Providing 24-hour high-quality service

User-friendly online submission system

Fair and swift peer-review system

Efficient typesetting and proofreading procedure

Display of the result of downloads and visits, as well as the number of cited articles

Maximum dissemination of your research work

Submit your manuscript at: http://papersubmission.scirp.org/

Or contact gsc@scirp.org 